\title{
Quaking and PTB control overlapping splicing regulatory networks during muscle cell differentiation
}

\author{
MEGAN P. HALL, ROLAND J. NAGEL, W. SAMUEL FAGG, LILY SHIUE, MELISSA S. CLINE, RHONDA J. PERRIMAN, \\ JOHN PAUL DONOHUE, and MANUEL ARES JR. ${ }^{1}$ \\ RNA Center, Department of Molecular, Cell, and Developmental Biology, Sinsheimer Labs, University of California, Santa Cruz, California \\ 95064, USA
}

\begin{abstract}
Alternative splicing contributes to muscle development, but a complete set of muscle-splicing factors and their combinatorial interactions are unknown. Previous work identified ACUAA ("STAR" motif) as an enriched intron sequence near musclespecific alternative exons such as Capzb exon 9. Mass spectrometry of myoblast proteins selected by the Capzb exon 9 intron via RNA affinity chromatography identifies Quaking (QK), a protein known to regulate mRNA function through ACUAA motifs in 3' UTRs. We find that QK promotes inclusion of Capzb exon 9 in opposition to repression by polypyrimidine tract-binding protein (PTB). QK depletion alters inclusion of 406 cassette exons whose adjacent intron sequences are also enriched in ACUAA motifs. During differentiation of myoblasts to myotubes, QK levels increase two- to threefold, suggesting a mechanism for QK-responsive exon regulation. Combined analysis of the PTB- and QK-splicing regulatory networks during myogenesis suggests that $39 \%$ of regulated exons are under the control of one or both of these splicing factors. This work provides the first evidence that QK is a global regulator of splicing during muscle development in vertebrates and shows how overlapping splicing regulatory networks contribute to gene expression programs during differentiation.
\end{abstract}

Keywords: alternative splicing; myogenesis; splicing silencer; splicing enhancer

\section{INTRODUCTION}

Alternative pre-mRNA splicing is regulated to control both the quantity and the coding potential of mRNAs from a gene. Quantity of mRNA can be controlled by regulating splicing that creates mRNA forms with premature stop codons, turning genes off by the nonsense-mediated decay pathway (Lewis et al. 2003; Lejeune and Maquat 2005; Ni et al. 2007). Coding potential can be controlled by regulating alternative exons to produce mRNAs for distinct proteins from the same gene, expanding the proteome in metazoans (Black 2003; Nilsen and Graveley 2010). Understanding the potential for alternative splicing to regulate important processes is only the first step toward an integrated view of how it is coordinated in complex systems (Kalsotra and Cooper 2011). There is a long but incomplete list of splicing factors, each with a complex set of cooperative and antagonistic relationships with other splicing factors that seem distinct at different regulatory sites and in different tissues. Several splicing factors act at other steps in gene expression, for example, binding to mRNA-untranslated regions to affect nuclear export, localization, stability, and translation (e.g., Sanford et al. 2005). Conversely,

\footnotetext{
${ }^{1}$ Corresponding author

E-mail ares@ucsc.edu

Article published online ahead of print. Article and publication date are at http://www.rnajournal.org/cgi/doi/10.1261/rna.038422.113.
}

many RNA-binding proteins not characterized as splicing factors might yet be shown to regulate splicing.

Muscle cells have evolved alternative splicing for making specialized forms of cytoskeletal and mitochondrial proteins necessary for building, energizing, and controlling the contractile apparatus, such as the $\alpha$-actinin SM exon, $\alpha$-tropomyosin exon 2, and cardiac troponin T exon 5 (Gooding et al. 1998; Southby et al. 1999; Charlet-B et al. 2002). Inclusion of $\alpha$-tropomyosin exon 2 is regulated in part by the antagonistic action of SFRS7 with hnRNPs $\mathrm{H}$ and $\mathrm{F}$ (Crawford and Patton 2006). Similarly, antagonism between PTB, CUG-BP1, MBNL1, and the CELF proteins regulates $\alpha$-actinin splicing (Gromak et al. 2003). Cardiac troponin T is regulated by the opposing actions of CUG-BP2 and MBNL1 (Goo and Cooper 2009; Warf et al. 2009). A variety of other alternative splicing factors are expressed in muscle cells (e.g., MBNL2, RBFOX1, RBFOX2). Thus far, none of the proteins known to function as splicing factors in vertebrate muscle recognize the ACUAA motif that we identified near mouse heart and skeletal muscle-specific exons (Sugnet et al. 2006).

A role in splicing regulation is suspected for sequences related to the ACUAA motif since they appear enriched downstream from muscle exons (Sugnet et al. 2006; Das et al. 2007), downstream from alternatively spliced exons in general (Voelker and Berglund 2007), and upstream of exons that are spliced in hESCs but not other ES cell types (Yeo et al. 2007), as 
well as near exons activated during differentiation of $\mathrm{C} 2 \mathrm{C} 12$ myoblasts to myotubes in vitro (Bland et al. 2010). This sequence has been called the "STAR" motif because it is contained within a more general binding site consensus for members of the mammalian STAR (Signal Transduction and Activation of RNA) family of proteins (Vernet and Artzt 1997). Despite its bioinformatic identification, direct evidence for its function and the identity of protein factors that might act through it are not available.

We investigated the role of the ACUAA motif in C2C12 myoblasts by searching for proteins that bind a natural intron RNA region containing it. This effort identified the RNAbinding protein $\mathrm{QK}$ as a muscle-splicing factor acting directly through ACUAA motifs near the exons that it controls. Unlike in oligodendrocytes, where $\mathrm{QK}$ affects splicing by controlling the expression of the direct splicing regulator hnRNPA1 through its mRNA 3' UTR (Zhao et al. 2010; Zearfoss et al. 2011), QK acts both positively and negatively as a direct splicing regulator through intronic splicing enhancers and silencers in muscle precursor cells. The changes in alternative splicing at QK-regulated exons during myogenesis are likely due to an increase in QK expression. Levels of the splicing factor PTB are reduced during myogenesis (Boutz et al. 2007a), and its regulatory network overlaps that of QK, such that the net regulation of a subset of QK-dependent exons is further refined by relief of PTB repression during myogenesis.

\section{RESULTS}

\section{Capzb exon 9 is a muscle-activated exon with conserved ACUAA motifs downstream}

To study the role of ACUAA motifs in splicing, we chose exon 9 from the $C a p z b$ gene as a model. Capzb encodes an actin filament capping protein; its $\mathrm{C}$ terminus is altered by alternative inclusion of exon 9 in heart and skeletal muscle (Schafer et al. 1994). Capzb exon 9 was identified as a muscle- and heart-specific exon with adjacent ACUAA elements in our study on splicing in adult tissues (Sugnet et al. 2006). We confirmed the activation of $C a p z b$ exon 9 during differentiation of C2C12 myoblasts (Fig. 1A; Bland et al. 2010) by RT-PCR (Fig. 1B). Alignment of sequences downstream from the $C a p z b$ exon from mouse and other vertebrates reveals conservation of multiple copies of the ACUAA element (Fig. 1C).

\section{ACUAA motifs are required for exon inclusion}

To determine whether the ACUAA elements downstream from $C a p z b$ exon 9 contribute to proper splicing of this exon, we used a $\beta$-globin reporter system (Dominski and Kole 1991), inserting Capzb exon 9 along with adjacent intron sequences $\sim 200$ nucleotides upstream and $\sim 250$ nucleotides downstream, between human $\beta$-globin exons (Fig. 2A). A series of mutations focusing on the conserved region from 32 to 72 nucleotides downstream from Capzb exon 9 containing the
ACUAA motifs was tested by transfection into proliferating C2C12 myoblasts, followed by RT-PCR (Fig. 2B). The wildtype reporter includes the Capzb exon at $\sim 8 \%$ in myoblasts (Fig. 2B, lane 3). Deletion of the conserved region (D1), replacing the conserved region with a nonspecific sequence (R1), or deleting just the ACUAA elements (M-Czb) results in loss of exon inclusion (Fig. 2B, lanes 4-6). These data indicate that the ACUAA motifs downstream from the Capzb exon are required for its proper inclusion in myoblasts, as suggested by their enrichment near a large class of regulated exons (Sugnet et al. 2006; Das et al. 2007).

\section{Quaking and SF1 bind specifically to RNA containing ACUAA motifs}

To identify proteins that bind ACUAA containing RNA, we used RNA affinity chromatography, followed by multidimensional protein identification technology (MudPIT) (Washburn et al. 2001). RNAs containing either the wild-type $C a p z b$ sequence from 32 to 72 nucleotides downstream from exon 9 (Fig. 3A, WT) or with mutated ACUAA motifs (Fig. 3A, M) were coupled to agarose beads and incubated with myoblast nuclear extracts. Proteins bound at low salt were released with increasing salt concentrations (Fig. 3B), and the WT and M fractions were compared on a silverstained gel. The pattern of proteins eluted remains complex; however, specific proteins can be seen in the WT- but not the M-RNA-binding fractions (Fig. 3B, arrow). We chose to analyze the $0.4 \mathrm{M} \mathrm{NaCl}$ eluted fraction (Fig. 3B, asterisk) by MudPIT (Yates et al. 2009).
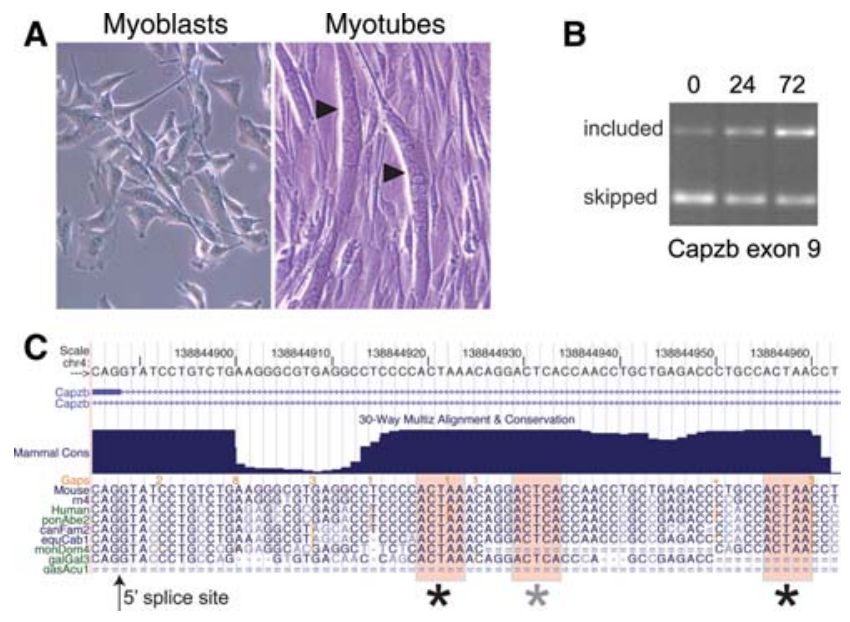

FIGURE 1. Capzb exon 9 is activated during myogenesis and has intronic ACUAA elements. (A) Phase contrast photographs of proliferating $\mathrm{C} 2 \mathrm{C} 12$ or cells treated with low serum for $72 \mathrm{~h}$ to induce myogenesis. Multinucleate myotubes are indicated by arrowheads. (B) RT-PCR measurement of changes in Capzb exon 9 inclusion during differentiation using primers in exons 8 and 10 of the endogenous Capzb gene. Exon 9 inclusion increases during differentiation. $(C)$ Alignment of intronic sequences downstream from the $5^{\prime}$ splice site bordering $C a p z b$ exon 9 from several vertebrates. The ACUAA elements are shaded and marked with asterisks. 


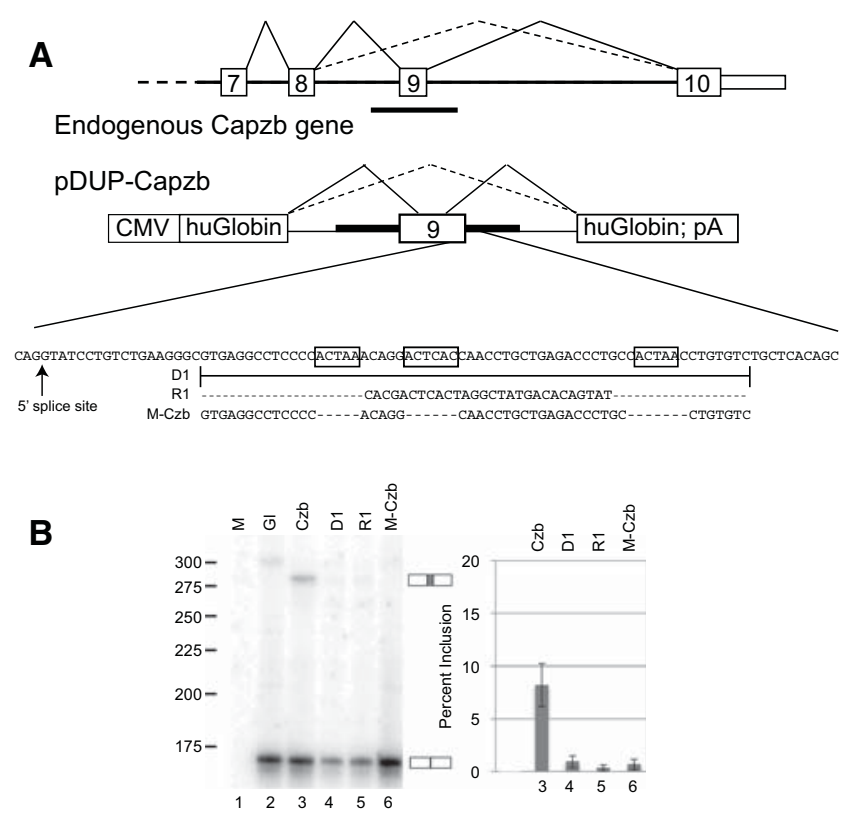

FIGURE 2. Splicing reporters based on Capzb exon 9. (A) Cartoon of $C a p z b$ gene structure from exons 7 through 10 . The region marked by the black bar below the endogenous gene was amplified by PCR and cloned into pDUP51 to create the reporter construct shown. The sequence below the reporter diagram represents the downstream intronic region containing the ACUAA elements (boxed). Mutations tested are (D1) deletion of the conserved region; (R1) replacement of the conserved region with a nonspecific sequence; (M-Czb) deletion of the ACUAA elements. (B) RNA isolated from proliferating $\mathrm{C} 2 \mathrm{C} 12$ cells transiently transfected with the constructs in $A$ were analyzed by RT-PCR using primers specific for the flanking $\beta$-globin exons; spliced products are indicated to the right of the gel. Exon percent inclusion for each lane is graphed, far right. Mock-transfected and globin-only controls are shown (M, Gl, lanes 1,2); the band in the Gl lane is nonspecific.

We expected a complex set of proteins to bind to RNA under these conditions; indeed, numerous cytoskeletal proteins, ribosomal proteins, and DNA-binding proteins are found in both fractions (data not shown). To examine the relative association of RNA processing factors with the WT- and MRNAs, we considered five classes of proteins: splicing factors, hnRNP proteins, spliceosomal snRNP proteins, DEAD/H RNA helicase family proteins, and other processing enzymes (Table 1; Supplemental Table 1). Among proteins detected in the WT-RNA fraction, but absent from the M-RNA fraction, are the known ACUAA-binding factors QK (Ryder and Williamson 2004; Galarneau and Richard 2005) and Splicing Factor 1 (SF1) (Arning et al. 1996; Liu et al. 2001; Corioni et al. 2011). The peptides observed for the QK protein do not distinguish which of the three major $\mathrm{QK}$ isoforms (QK-5, QK-6, and QK-7) are bound, since these forms differ only in their C-terminal tails (Ebersole et al. 1996; Chénard and Richard 2008).

We validated several proteins from the MudPIT analysis by Western blot using fractions from the WT- and M-RNA columns. QK and SF1 were well retained by the WT- but not the M-RNA affinity matrix (Fig. 3C). Thus, it appears that QK, SF1, and several other proteins depend on the intact ACUAA elements for their efficient association with the WT-RNA. Whether these bind directly to RNA or indirectly to other proteins bound to RNA is not known. hnRNP K and Ddx 5 were retained by both of the matrices, although it appears the M-RNA matrix bound less protein overall. Furthermore, the known splicing regulator PTB is bound by the Capzb RNA sequence but is not strongly dependent on the ACUAA sequences (Fig. 3C). We conclude that QK, SF1, PTB, as well as other proteins, bind pre-mRNA sequences downstream from Capzb exon 9 and are candidates for factors that regulate its splicing.

\section{Depletion of QK, but not SF1, inhibits Capzb exon 9 inclusion in myoblasts}

To test the hypothesis that QK activates Capzb exon 9 we used siRNA against QK (all isoforms) to deplete the protein in myoblasts. A Western blot using the pan-QK antibody shows substantial reduction in QK protein (Supplemental Fig. 1A), and RT-PCR analysis of the endogenous Capz $b$ transcripts reveals that inclusion of exon 9 is greatly inhibited (Fig. 4A, lane 3). In contrast, when we use siRNA to deplete SF1 in myoblasts, endogenous Capzb exon inclusion is unaffected (Fig. 4A, lane 4; Supplemental Fig. 1A), suggesting that SF1 does not activate exon inclusion through downstream ACUAA sequences. Thus, $\mathrm{QK}$, not $\mathrm{SF}$, is the ACUAA-binding protein that contributes to Capzb exon 9 inclusion in myoblasts.

\section{Quaking isoform 5 activates Capzb exon 9 through the ACUAA motif}

Given that reduction in QK protein levels decreases Capzb exon 9 inclusion, we asked whether increasing QK protein levels would promote inclusion. We focused on Quaking isoform 5 (QK-5) because it is predominantly nuclear, whereas isoforms 6 and 7 (QK-6, QK-7) are mostly cytoplasmic in cell types that have been tested (Chen and Richard 1998; Wu et al. 1999). We transfected a myc-tagged QK-5 construct (generous gift from Sean Ryder) along with wild-type and mutant Capzb reporter into myobloasts (Fig. 4B). Expression of myc-QK-5 results in a nearly eightfold increase in exon 9 inclusion (Fig. 4B, cf. lanes 4 and 5, $P<0.001, n=4$ ), while the $\mathrm{M}-\mathrm{Czb}$ reporter lacking the three ACUAA motifs was not affected (lanes 6 and 7, see Fig. 2 for a description of the M-Czb mutant). Thus, increased expression of QK-5 activates inclusion of Capzb exon 9 in a fashion dependent on the downstream intronic ACUAA sequences.

\section{Repression of PTB enhances QK activation of Capzb exon 9 inclusion}

RNA affinity chromatography detects PTB binding to the intronic sequence downstream from Capzb exon 9 (Fig. 3). $\mathrm{PTB}$ represses exons in $\mathrm{C} 2 \mathrm{C} 12$ myoblasts (Boutz et al. 


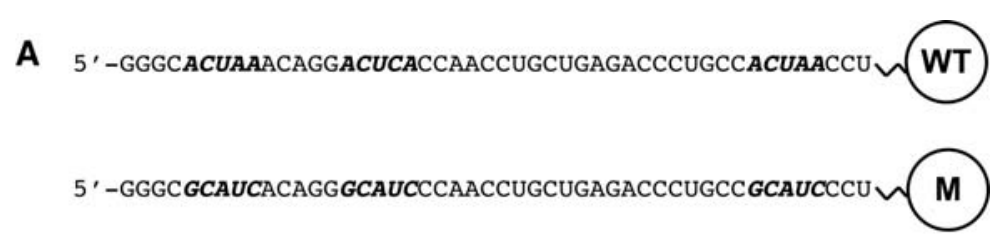

B

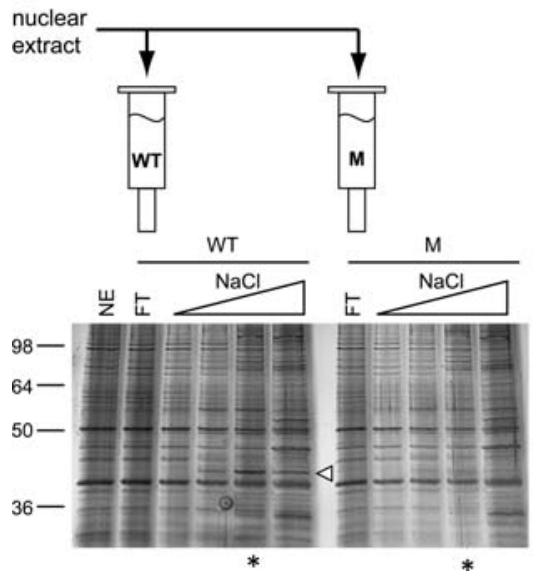

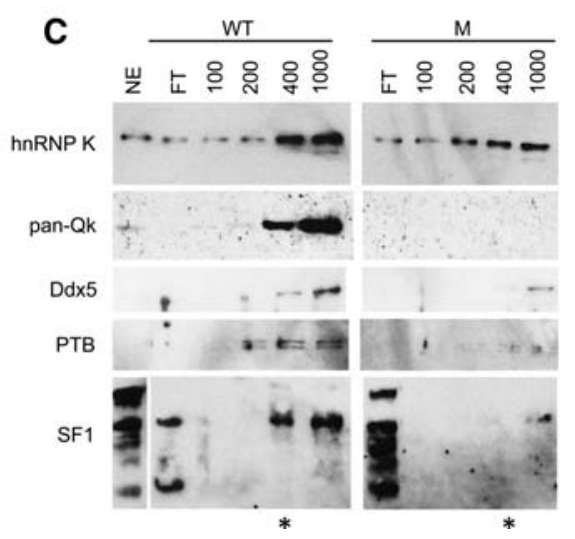

FIGURE 3. Identification of ACUAA-binding proteins in proliferating $\mathrm{C} 2 \mathrm{C} 12$ cells. $(A)$ Sequences of in vitro-transcribed RNAs used. ACUAA motifs or mutant versions are italicized. (B) Silver-stained denaturing gel of proteins bound to the wild-type (WT) or mutant (M) RNAs. Lanes are as follows: NE, nuclear extract; FT, flow through; triangles indicate increasing $\mathrm{NaCl}$ elution $(0.1,0.2,0.4$, and $1 \mathrm{M})$. Arrow points to enriched proteins visible in the WTbut not the M-RNA-binding fractions. Asterisks mark fractions subjected to MudPIT analysis. $(C)$ Western blot of hnRNP K, QK, Ddx5, SF1, and PTB in the eluted fractions. Lanes correlate with those in $B$.

2007a), and PTB repression can be mediated through downstream sites in combination with upstream binding sites (Chan and Black 1997; Southby et al. 1999). To test whether Capzb exon 9 is under the control of PTB, we depleted PTB from myoblasts with or without concomitant overexpression of QK-5 (Fig. 4C,D). After confirming the effects on protein levels by Western blot (Fig. 4C, lanes 4-7), we analyzed splicing of the Capzb exon 9 reporter construct by RT-PCR (Fig. $4 \mathrm{D}$, lanes 4-7). When PTB expression is reduced, inclusion levels increase approximately fourfold (Fig. 4D, cf. lanes 4 and 5, $P<0.0001, n=4)$. As discussed above, increased QK-5 expression activates the Capzb exon 9 reporter on its own (Fig. 4D, cf. lanes 4 and 6). However, in combination with reduced PTB expression, increased QK-5 expression leads to greater exon inclusion (Fig. 4D, cf. lanes 3 and 7 , $P<0.002, n=4)$. Similar results are obtained for the endogenous Capzb exon 9 (Supplemental Fig. 1B). This shows that PTB represses Capzb exon 9 antagonistically to QK. A model describing these relationships is shown in Figure 4E.

\section{QK depletion in myoblasts results in widespread alternative splicing changes}

To determine the extent of QK function in splicing, we depleted QK in proliferating $\mathrm{C} 2 \mathrm{C} 12$ cells and captured changes in alternative splicing using splicing-sensitive microarrays.
Western blots revealed that levels of all three isoforms are reduced by a QK-specific siRNA directed at a common region of their mRNAs (Fig. 5A). We detected 406 cassette exons whose inclusion changes in QK-depleted myoblasts as compared with the mock-depleted controls $(q \leq 0.05$ and $\mid$ Sepscore $\mid \geq 0.3$; Supplemental Table 2). We validated a number of these by RT-PCR (Fig. 5B). Among the 162 exons with the most significant changes $(q=0, \mid$ Sepscore $\mid \geq$ 0.5 ), about half show a decrease in inclusion upon QK depletion, indicating that QK promotes their inclusion in myoblasts. In contrast, half show an increase in exon inclusion, indicating that $\mathrm{QK}$ represses them. We conclude that QK has a major role in regulating splicing in muscle cells.

\section{Enrichment of intronic ACUAA sequences near QK-regulated exons}

If QK functions in muscle cells like other globally active splicing factors such as the MBNL (Du et al. 2010; Charizanis et al. 2012; Wang et al. 2012), RBFOX (Zhang et al. 2008; Yeo et al. 2009), PTB (Xue et al. 2009), and Nova proteins (Ule et al. 2006), we would expect to find QK-binding sites near the exons it controls. We searched for 5-mers enriched in the regions 150 nucleotides upstream of and downstream from the top 162 QK-regulated exons relative to the corresponding regions of 5166 cassette exons with probesets on the microarray. Significant $($ FDR $\leq 0.05)$ enrichment for CUAAC and ACUAA (and no other 5-mers) is found upstream of exons repressed by $\mathrm{QK}$ and downstream from exons activated by QK (Supplemental Table 3 ). We mapped the positional occurrence of the ACUAA 5mer across the entire set of QK-regulated exons relative to cassette exons whose splicing did not change upon QK depletion (Fig. 5C; Supplemental Table 3). In general, when QK binds upstream of an exon it acts as a repressor, and when bound downstream, it acts as an activator (Fig. 5C). This is comparable to other splicing factors that bind intron sequences, such as Nova, MBNL1, and others (Ule et al. 2006; Zhang et al. 2008; Xue et al. 2009; Yeo et al. 2009; Du et al. 2010; Charizanis et al. 2012; Wang et al. 2012). The distribution of ACUAA both upstream at QK silencers and downstream at QK enhancers is notably bimodal. This is likely due to the fact that $\mathrm{QK}$ is a dimer with a bipartitbinding site (Zorn and Krieg 1997; Chen and Richard 1998; Galarneau and Richard 2005; Carmel et al. 2010; Beuck et al. 2012). 
TABLE 1. Detection of RNA processing factors in WT- and M-RNA affinity chromatography fractions

\begin{tabular}{|c|c|c|c|}
\hline Group & Only WT RNA & Both & Only M RNA \\
\hline Splicing factors & $\underline{\text { SF1, KHDRBS1, PTBP2, TIAL1 }}$ & $\begin{array}{l}\frac{\text { PTBP1, SFPQ, SFRS1, SFRS2, SFRS3, SRRM2, }}{\text { U2AF2 }} \\
\text { KHSRP, SFRS6 }\end{array}$ & CELF2, MBNL1 \\
\hline HnRNP proteins & HNRNPDL & $\begin{array}{l}\text { HNRNPK, HNRNPA1, HNRNPA2B1, HNRNPA3, } \\
\text { HNRNPH1, HNRNPH2, PCBP1, PCBP2 } \\
\text { HNRNPA0, HNRNPAB, HNRNPD, HNRNPF, } \\
\text { HNRNPL, HNRNPL1, HNRNPM, HNRNPR, } \\
\text { HNRNPU }\end{array}$ & HNRNPC \\
\hline $\begin{array}{l}\text { SnRNP and } \\
\text { spliceosomal } \\
\text { proteins }\end{array}$ & SNRPB, SNRPC, SNRPD3, SNRPE & $\begin{array}{l}\text { SNRPD2, SNRNP70, SNRPA1 } \\
\text { PRPF6, PRPF8, SF3A1, SF3B1, SF3B2, SF3B3, } \\
\text { SNRNP200 }\end{array}$ & \\
\hline DEAD/H proteins & DDX3Y, DDX18 & $\begin{array}{l}\text { DDX5, DDX17, DDX21 } \\
\text { DDX1, DDX4, DHX9, DHX15, DDX23 }\end{array}$ & $\begin{array}{l}\text { DDX6, DDX46, } \\
\text { DDX58 }\end{array}$ \\
\hline Other & $\begin{array}{l}\text { QK, CSTF2 } \\
\text { ADAR, CPSF7, ELAVL1, EWSR1, EXOSC9, } \\
\quad \text { IGF2BP2, IGF2BP3, PABPC2, SART1 }\end{array}$ & $\begin{array}{l}\text { ADARB1, CPSF6, CSDE1, DEK, PARP1, PSPC1, } \\
\text { RBMS1, RBMS2, SERBP1, STAU1 }\end{array}$ & $\begin{array}{l}\text { KHDRBS3, } \\
\text { RBM39, SSB }\end{array}$ \\
\hline
\end{tabular}

Bold indicates that peptides covering $>10 \%$ of the coding region were detected. Underlined proteins were validated by Western blot (see Fig. 3 ).

\section{The PTB and QK splicing regulatory networks overlap in myoblasts}

Capzb exon 9 inclusion is controlled in myoblasts by a balance between QK activation and PTB repression and is induced during myoblast differentiation to myotubes. In addition, PTB down-regulation and several PTB-regulated splicing changes take place during myoblast differentiation (Boutz et al. 2007a). To explore the extent of PTB-splicing regulation in myoblasts, we used splicing-sensitive microarrays to analyze splicing changes after PTB depletion by siRNA (Supplemental Fig. 2A). Depletion of PTB results in splicing changes for 485 cassette exons $(q=0, \mid$ Sepscore $\mid \geq$ 0.5; Supplemental Table 4), of which 268 show increased inclusion (repressed by PTB), and 217 show decreased inclusion (activated by PTB). A number of 5-mers including UCUCU are significantly enriched in regions upstream of PTB repressed exons $($ FDR $<0.01$; Supplemental Table 5), and a map of the UCUCU frequency over the intronic regions adjacent to PTB repressed exons shows a broad region from $\sim 100$ nucleotides upstream and up to the $3^{\prime}$ splice site where this signal is located (Supplemental Fig. 2B; Supplemental Table 5). Our results for myoblasts are similar to analyses of PTB in other cell types and tissues (Boutz et al. 2007b; Xue et al. 2009; Llorian et al. 2010).

When we intersect the QK-splicing network with the PTB-splicing network (Supplemental Table 6), we find 172 exons whose inclusion is significantly affected $(q \leq 0.05$, $\mid$ Sepscore $\mid \geq 0.3$ ) by either QK or PTB depletion, including Capzb exon 9. As expected (Fig. 4), Capzb exon 9 is activated by QK and repressed by PTB. The 172 jointly regulated exons represent $42 \%$ of the $406 \mathrm{QK}$-regulated events, but only $17 \%$ of the 1012 PTB-regulated events, indicating that while the PTB network detected in this experiment is more than twice as large as the $\mathrm{QK}$ network, $\mathrm{QK}$ regulation is more strongly in- fluenced by PTB than the other way around. Interestingly, these exons sort out about equally into the four regulatory classes that could be created by the combination of $\mathrm{QK}$ and PTB (40 exons are activated by both, 40 are repressed by both, 48 are activated by QK and repressed by PTB, 44 are repressed by $\mathrm{QK}$ and activated by $\mathrm{PTB}$ ). Thus, Capzb is not unique; there are substantial numbers of exons controlled by QK and PTB in all possible combinatorial classes.

\section{Contributions of QK and PTB to alternative splicing during myoblast differentiation}

The analysis above details QK- and PTB-controlled splicing events in myoblasts. To assess their roles in alternative splicing during muscle cell differentiation, we asked which exons under QK and PTB control in myoblasts are also regulated during myogenesis. Regulation of PTB levels has been implicated in controlling several alternative splicing events in myogenesis (Boutz et al. 2007a). We compared splicing in RNA from myoblasts to that from 72-h differentiated myotubes using the same array platform as for the depletion experiments and detected many robust splicing changes, as also reported by groups using other platforms (Bland et al. 2010; Trapnell et al. 2010). Data for cassette exons showing changes in inclusion in myoblasts depleted of either QK or PTB or after differentiation into myotubes are shown in Supplemental Table 6.

We followed changes in $\mathrm{QK}$ protein expression during myogenesis by Western blot using the pan-QK antibody on proteins from undifferentiated myoblasts and $72 \mathrm{~h}$ myotube cultures (Fig. 6A). The upper band represents both QK-5 and QK-7, while the lower band represents QK-6. Relative to GAPDH, QK levels increase two- to threefold during differentiation. This increase might be expected to influence inclusion of the many exons controlled by QK in myoblasts in the 
A

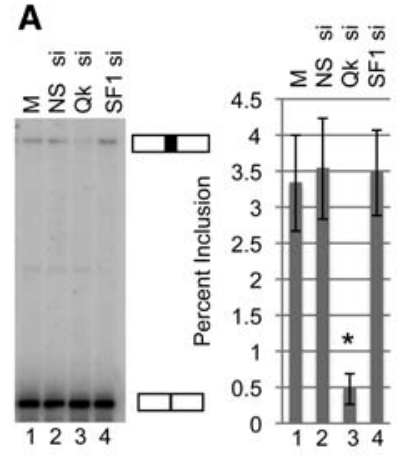

C

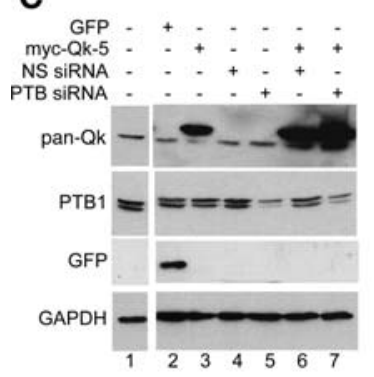

B
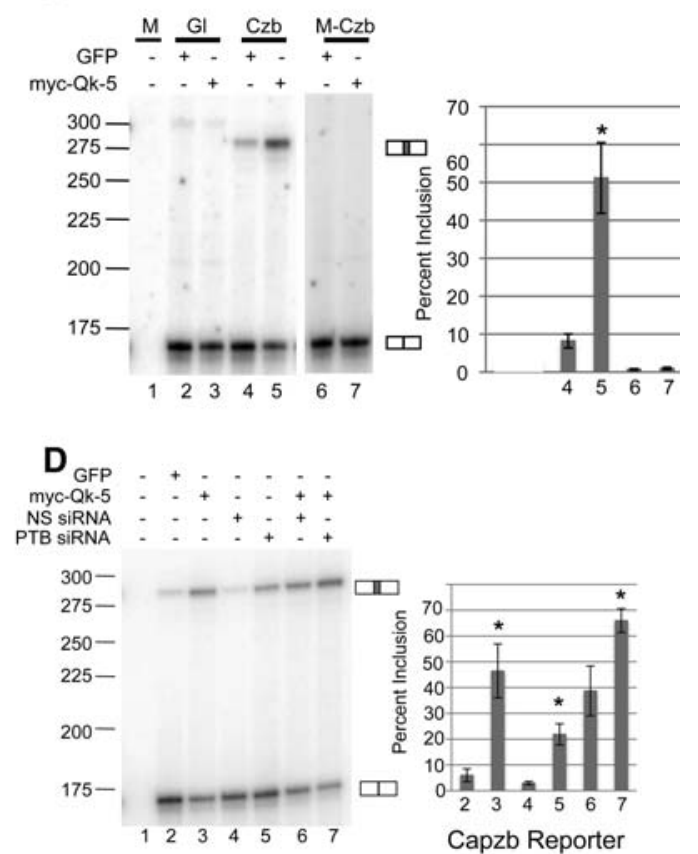

\section{E Capzb}

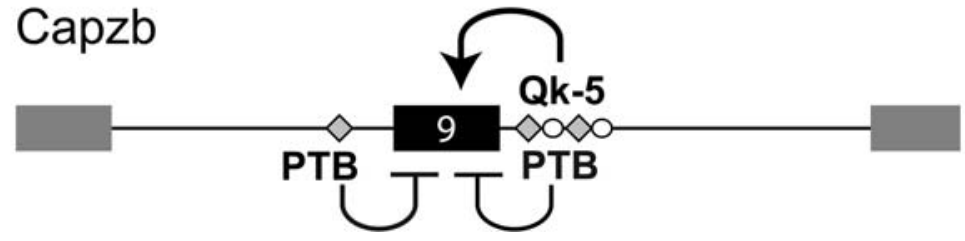

FIGURE 4. QK and PTB control inclusion of Capzb exon 9. (A) Analysis of RT-PCR products from $\mathrm{C} 2 \mathrm{C} 12$ cells mock-transfected $(\mathrm{M})$ or transiently transfected with a nonspecific siRNA (NS si), a QK-specific siRNA (QK si), or an SF1-specific siRNA (SF1 si). Spliced products corresponding to exon 9-included or excluded endogenous Capzb mRNAs are indicated to the right of the gel. Percent inclusion was quantified and graphed, far right. (B) Overexpression of QK leads to Capzb exon 9 inclusion provided ACUAA elements are intact. Proliferating C2C12 cells were mock transfected $(\mathrm{M})$ or transiently cotransfected with a QK-5 expression construct (mycQK-5) or a control GFP expression construct (GFP), along with either the wild-type Capzb reporter $(\mathrm{Czb})$ or the mutant reporter with deletion of the ACUAA elements (M-Czb) from Figure 2. A globin-only control is also shown (Gl, lanes 2,3); the band in the Gl lanes is a nonspecific RT-PCR product. Inclusion of the WT Capzb exon increased with expression of QK by approximately fivefold (cf. lanes 4 and $5, P<0.001, n=4$ ). Spliced products are indicated and percent inclusion is graphed, far right. QK depletion significantly reduces exon inclusion (asterisk, $P<0.05$, cf. lanes 2 and 3$)$. (C) Western blot of whole-cell extract from cells mock-transfected (lane 1) or transiently cotransfected with the Capzb reporter and either a GFP expression construct (GFP), a QK-5 expression construct (myc-QK-5), a nonspecific siRNA (NS siRNA), or a PTB-specific siRNA (PTB siRNA) as indicated at top. Blots were probed with antibodies to GFP, pan-QK, PTB, and GAPDH as a loading control (as indicated to the left of the blots). (D) Analysis of RT-PCR products from RNA isolated from cells transfected in $C$. Spliced products are indicated to the right of the gel. Percent inclusion was quantified and graphed, far right. $\left(^{*}\right) P<0.002$. (E) Model for regulation of Capzb exon 9 by QK and PTB. QK activates inclusion through intronic ACUAA elements downstream, and PTB represses inclusion, possibly through sequences similar to PTB-binding sites upstream and/or through binding downstream, as detected by RNA affinity chromatography (Fig. 3).

opposite direction as observed in QK-depleted myoblasts. Conversely, since PTB is down-regulated during myogenesis (Fig. 6A; Boutz et al. 2007a), the splicing of exons controlled by PTB in myoblasts may change in the same direction as observed in PTB-depleted myoblasts. For exons where QK and PTB appear to act similarly, exon inclusion may not change, as the increase in QK might offset the loss of PTB. Finally, the behavior of some exons may be influenced by other factors in addition to QK or PTB during differentiation.

We classified exons with respect to their dependence on these two splicing factors in myoblasts and their changes during muscle cell differentiation by clustering the Sepscores of exons whose inclusion changed in at least two of the three comparisons (Fig. 6B; Supplemental Table 7). Several expected classes are visible. For example, a subset of the exons activated by QK (decreased inclusion after depletion, blue), but not significantly affected by PTB (black) in myoblasts, is also activated during myotube differentiation (yellow), in part due to increasing QK protein (Fig. $6 \mathrm{~B}$, purple circle). A large group of exons is not significantly controlled by QK, but repressed by PTB in myoblasts (increased after depletion, yellow) and activated during differentiation (yellow), likely in part by the decrease in PTB protein (Fig. 6B, green circle; Boutz et al. 2007a). Other expected classes such as would be generated by increased QK repression or loss of PTB activation during differentiation can also be observed (Fig. 6B, white and blue circles). The combined regulatory effect of both factors explains another set of events (e.g., Fig. 6B, yellow circle). In total, $22 \%$ of the splicing changes observed during myoblast differentiation occur in exons controlled by $\mathrm{QK}$ or PTB and are consistent with the changes in QK and PTB protein levels during differentiation. The observed 72-h splicing changes of another $17 \%$ of exons that are also regulated by $\mathrm{QK}$ or PTB in myoblasts cannot be explained by the simple expectation that the increase in QK and the reduction in PTB relative to the myoblast state will predict the differentiated cell state; these exons may be influenced by other splicing factors also expressed in $\mathrm{C} 2 \mathrm{C} 12$ cells such as RBFOX and MBNL family members.

To identify exons whose inclusion during differentiation is likely altered by changes in activity of both QK and PTB, we 


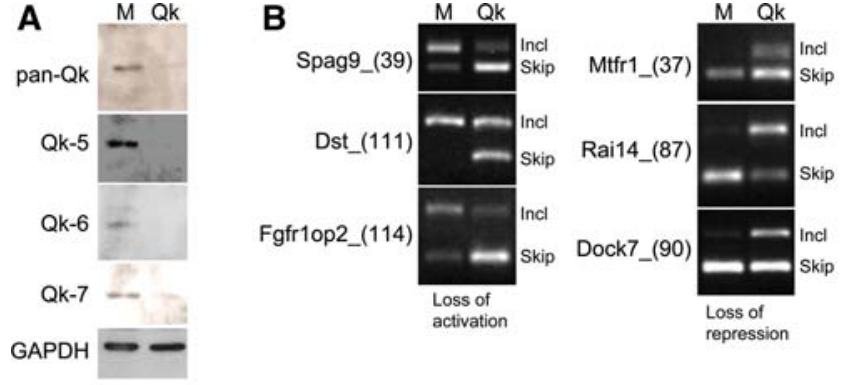

C ACUAA Motif distribution among Qk regulated exons

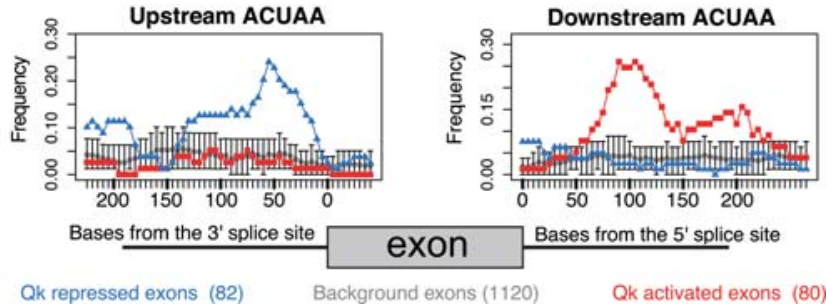

FIGURE 5. The QK-splicing regulatory network in proliferating myoblasts. (A) QK siRNA depletes all three forms of QK in myoblasts. Western blot of proteins from proliferating $\mathrm{C} 2 \mathrm{C} 12$ cells mock-transfected $(\mathrm{M})$ or transfected with a QK-specific siRNA (QK). Blots were probed with antibodies to pan-QK, QK-5, QK-6, QK-7, and GAPDH as a loading control. (B) RT-PCR validation of splicing changes detected by array analysis. Agarose gel analysis of RT-PCR products for alternative cassette exons using RNA from mock-transfected or QK-depleted cells. Exon-included product is always the upper band, exon-skipped product always the lower. The splicing event is labeled by gene name and exon number and size (nucleotides, in parenthesis). (C) The frequency of ACUAA elements upstream of (left) and downstream from (right) the top 162 QK-regulated cassette exons is mapped. Exons upregulated by QK depletion are in blue and inferred to be repressed by QK; down-regulated exons are in red and inferred to be activated by QK. Control exons are in gray. Error bars indicate the 95\% confidence limit for ACUAA frequency in the control exons.

made a three-dimensional plot of Sepscores for the 66 exons whose splicing changed in all three experiments (Fig. 6C; Supplemental Table 8), allowing the diversity of exon responses to be visualized. There are 10 exons (blue spheres) whose inclusion decreases upon QK depletion and increases upon PTB depletion, which are activated during differentiation, including Capzb exon 9 (Capzb_(113)). The behavior of these exons are consonant with the changes in protein level observed during differentiation or depletion in undifferentiated cells. As with the clustering (Fig. 6B; same exons are marked by asterisks), we observe many combinations of splicing changes within the three experimental conditions, many of which are not consonant with the changes in protein level during differentiation. For example, the Slain2_(78) exon (colored in green) is repressed by QK (exon inclusion increases upon QK depletion) and activated by PTB (exon inclusion decreases upon PTB depletion), but is activated during differentiation. Thus the robust activation of Slain2_(78) must be due to other factors that overcome strong repression due to increasing levels of QK and loss of activation with de- creasing levels of PTB. This highlights the incomplete nature of our understanding of splicing regulation during muscle cell differentiation and underscores its complexity. Nonetheless, in this more select set of exons, we again observe that the differentiation behavior of a large number of exons (29\%) can be explained by changes in QK and PTB protein levels during differentiation (Fig. 6C; Supplemental Table 8).

\section{DISCUSSION}

In a previous study we used genome-wide splicing data from mouse tissues to identify motifs associated with heart and skeletal muscle-specific exons, revealing an RNA sequence motif ACUAA similar to those recognized by SF1 and the STAR family of RNA-binding proteins (Sugnet et al. 2006). We have now shown that this motif mediates splicing regulatory control through $\mathrm{QK}$, in particular the nuclear isoform 5 (QK-5). At Capzb exon 9 the conserved downstream ACUAA elements are required for exon inclusion, bind $\mathrm{QK}$ in a fashion dependent on ACUAA, and mediate QK-5 activation (Figs. 2-4; Supplemental Fig. 1). Furthermore, QK regulates hundreds of splicing events in muscle cells, as a repressor or an activator, depending on the location of nearby ACUAA motifs (Fig. 5; Supplemental Tables 3, 4). We found that QK protein levels change during differentiation of myoblasts to myotubes (Fig. 6), suggesting a mechanism for a part of the alternative splicing program during myotube differentiation. Finally, we intersected the QK splicing regulatory network with that of PTB, a splicing factor that is down-regulated during myogenesis (Boutz et al. 2007a), and found classes of exons controlled by both proteins (Fig. 6). This work identifies QK as a global splicing factor in muscle cells and reveals that QK plays a larger role beyond its known activity as a translational regulator binding to $3^{\prime}$ UTRs.

\section{QK RNA-binding proteins are ancient regulators of fundamental processes}

Mouse Quaking was originally identified as a recessive mutation causing a jittery phenotype attributed to dysmyelination in the central nervous system (Sidman et al. 1964). Quaking has been implicated in a striking variety of processes in the mouse, such as embryogenesis, blood vessel development, glial cell fate determination, apoptosis, and smooth muscle development, while the human homolog, QKI, has been implicated in a number of diseases, including ataxia, glioblastoma development, and schizophrenia (Chénard and Richard 2008). QK homologs are expressed in genomes as divergent as sea urchin and are critically involved in fundamental cell and developmental processes in deeply diverged metazoans from C. elegans ( $g l d-1$, asd-2) (Francis et al. 1995; Ohno et al. 2008) to Drosophila (how) (Baehrecke 1997; Fyrberg et al. 1997; Zaffran et al. 1997) and zebrafish ( $q k A)$ (Tanaka et al. 1997; Lobbardi et al. 2011). In vertebrates, a larger family of proteins related to $\mathrm{QK}$ also exists, including SAM68 and 

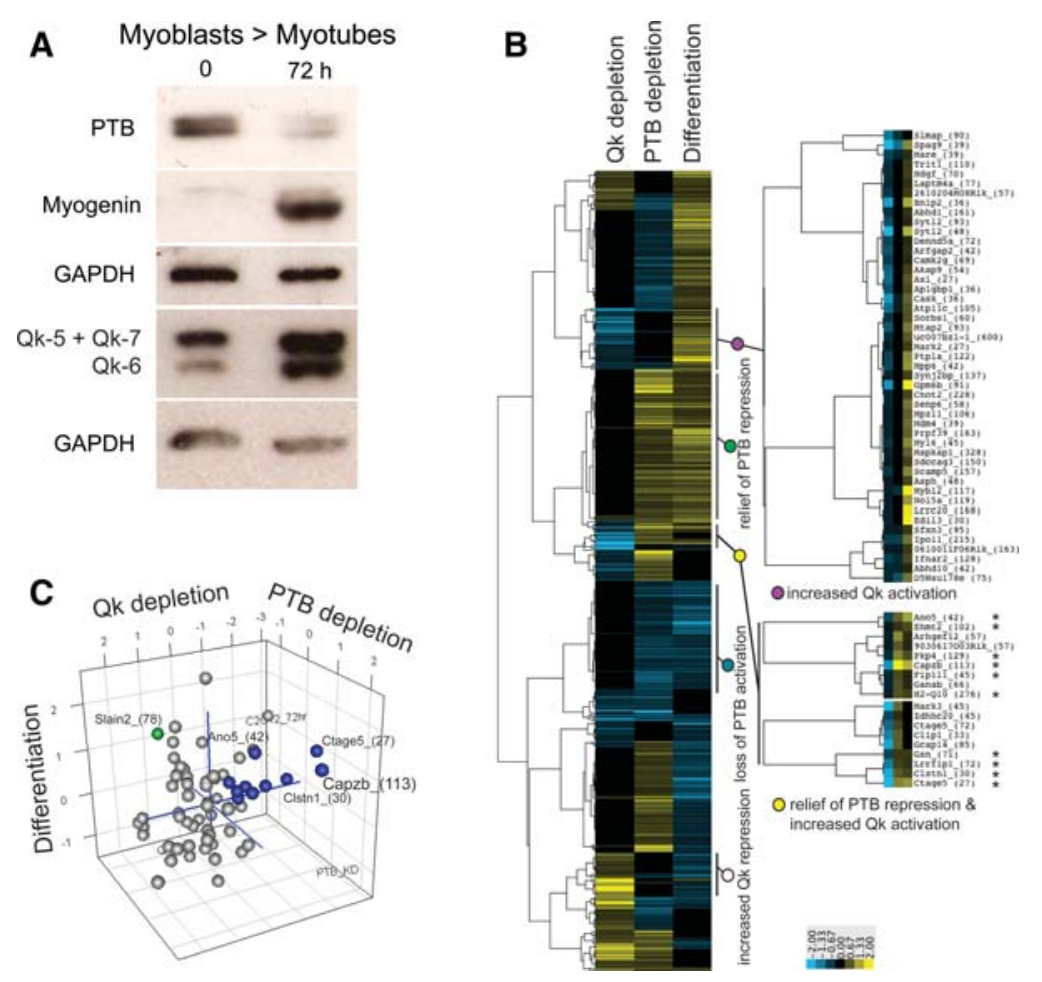

FIGURE 6. Regulation of QK protein level, PTB protein level, and alternative splicing during myogenic differentiation. (A) Western blot of proteins during differentiation. Proteins from undifferentiated C2C12 Myoblasts (0) or cells after $72 \mathrm{~h}$ of differentiation (Myotubes, $72 \mathrm{~h}$ ) were detected using antibodies against proteins listed at left: PTB, myogenin, pan-QK (co-migration of QK-5 and QK-7 results in one band, QK-6 is the lower band), and GAPDH. (B) Clustering of splicing events based on their response to QK or PTB depletion in myoblasts relative to their change in splicing during differentiation. Yellow means that inclusion increased, whereas blue indicates reduction in exon inclusion. Asterisks mark exons colored blue in C. A total of 612 cassette exon events with significant changes ( $q$-value $\leq 0.05$ and $\mid$ Sepscore $\mid \geq 0.3$ ) in at least two data sets are shown; Sepscores that did not meet the significance criteria were replaced with zeros for clustering (Supplemental Table 7). (C) Graph of exons with splicing changes in all three data sets. The Sepscores of 66 exons with $q$-value $\leq 0.01$ and $\mid$ Sepscore $\mid \geq 0.3$ in all three data sets were plotted using R. Exons activated by QK and repressed by PTB in myoblasts that are activated during differentiation are blue. The Slain2_(78) exon is green. ments related to the ACUAA motif are found in many contexts, bound by different proteins, making it difficult to predict the binding partner of the ACUAA motif observed bioinformatically (Sugnet et al. 2006; Das et al. 2007; Bland et al. 2010). For example, the branchpoint sequence URAY (in yeast, UACUAAC), found near exons and utilized in constitutive splicing during the first catalytic step, is bound by SF1 (in yeast, BBP1) to recruit the splicing machinery to the intron (Kramer 1992; Liu et al. 2001). The response element for QK and its C. elegans homolog GLD-1 (Ryder and Williamson 2004; Ryder et al. 2004) has been found in $3^{\prime}$ UTRs, where it regulates mRNA stability, localization, and translation (Saccomanno et al. 1999; Li et al. 2000; Lakiza et al. 2005; Zhao et al. 2010; Zearfoss et al. 2011). We found that both QK and SF1 bound the ACUAAlike sequences downstream from Capzb exon 9 by RNA affinity chromatography (Fig. 3). We then showed that depletion of SF1 has no detectable effect on Capzb exon 9 inclusion, while QK depletion strongly reduced exon inclusion (Fig. 4A,B). Furthermore, overexpression of the QK-5 isoform increased exon inclusion (Fig. 4D; Supplemental Fig. 1A), demonstrating a direct role for $\mathrm{QK}$ in regulating alternative splicing of Capzb exon 9. the less-studied SLM-1 and SLM-2 (Lock et al. 1996; Di Fruscio et al. 1999). Together, this evolutionary depth and breadth of functional contribution implies that QK and its relatives have been integrated into the post-transcriptional regulatory structure of eukaryotic cells for hundreds of millions of years. Here we show that in addition to its previously demonstrated role in translational control, that $\mathrm{QK}$ is a global regulator of splicing in vertebrate muscle cells during differentiation.

\section{QK is a splicing factor that directly activates Capzb exon 9}

The identifying feature of this ancient STAR protein family is a dimeric RNA-binding domain that recognizes bipartite sequences of the form AYUAAY..N2-20..UAAY (Zorn and Krieg 1997; Chen and Richard 1998; Galarneau and Richard 2005; Carmel et al. 2010; Beuck et al. 2012). Sequence ele-

\section{Direct and indirect modes of QK influence on splicing}

Several studies of invertebrate QK homologs have identified roles in splicing at specific exons. C. elegans asd-2 mutations were isolated using a two-color reporter gene carrying mutually exclusive exons from a body wall muscle myosin gene (Ohno et al. 2008). Mutations in an ACUAA-like motifcontaining element (two CUAAC repeats) were shown to abrogate the regulation of adult-specific alternative splicing, phenocopying the asd-2 mutant worms. In flies, the QK homolog how promotes inclusion of neurexin IV exon 3, most likely through downstream ACUAA sequences (Rodrigues et al. 2012). It has remained an open question as to whether these single exon studies reflect a larger involvement of QK in splicing at other exons more globally. In vertebrates, $\mathrm{QK}$ has been shown to regulate splicing in oligodendrocyte precursors, but not primarily by binding near exons with ACU AA. In these cells, QK stabilizes hnRNPA1 mRNA by binding 
to its 3' UTR; thus, a primary effect of depleting QK appears to be down-regulation of hnRNP A1, which causes gene expression and splicing defects (Zearfoss et al. 2011).

In myoblasts, however, introns neighboring the exons most affected by QK depletion are clearly enriched for the QKbinding site (Fig. 5) and exhibit the "upstream repressing, downstream activating" pattern observed for other globally active splicing factors like Nova (Ule et al. 2006), MBNL1 (Du et al. 2010), MBNL2 (Charizanis et al. 2012), RBFOX1 (Jin et al. 2003), and RBFOX2 (Zhang et al. 2008; Yeo et al. 2009). Splicing of Capzb exon 9 is influenced by the welldefined binding sites for QK (Ryder and Williamson 2004; Galarneau and Richard 2005) in the downstream intron and by expression of QK (Figs. 2B, 4; Supplemental Fig. 1). Thus, we infer that QK acts directly in myoblast splicing, rather than indirectly through hnRNP Al, as in both the Quaking viable mouse (Zhao et al. 2010) and oligodendrocyte precursor cells (Zhao et al. 2010; Zearfoss et al. 2011). This does not exclude the possibility that QK regulates other RNA-binding proteins in myoblasts-a view supported by our observation that a subset of exons is regulated by QK but lacks good matches to the QK response element within 150 nucleotides of their splice sites. These exons could be regulated by other factors that are themselves regulated by QK, or have QK-binding sites farther from the exon, as has been observed for RBFOX regulation (Huh and Hynes 1994; Lim and Sharp 1998; Tang et al. 2009). In addition, we note that a 5-mer related to the RBFOX motif UGCAUG is slightly enriched upstream of exons repressed by QK in myoblasts (Supplemental Table 3), suggesting that either these exons are coregulated by a QK and an RBFOX family member, or perhaps that QK might regulate an RBFOX family member. Clearly, the regulation and overlap of complexity of splicing during muscle differentiation is far from resolved.

\section{QK is a dual regulator of alternative splicing and mRNA function}

In mammals, RNA-binding proteins come in families (e.g., $\mathrm{PTB} / \mathrm{nPTB}$, RBFOX1 through RBFOX3, MBNL1 through MBBNL3); members of the same family share very similar RNA-binding domains and seem to bind indistinguishable motifs. Yet family members have both shared and distinct functions that are governed by sequence context, cell-type, or tissue-specific information. For example, MBNL1 appears to influence alternative pre-mRNA splicing more significantly in muscle tissue, whereas MBNL2 exerts a similarly predominant influence in brain tissue ( $\mathrm{Du}$ et al. 2010; Charizanis et al. 2012). In addition, numerous in vivo crosslinking studies on splicing factors show that many also bind to $3^{\prime}$ UTRs of mRNAs as well as to introns near regulated exons (Hafner et al. 2010; Charizanis et al. 2012; Masuda et al. 2012; Wang et al. 2012). This implies that the same protein may function in splicing, localization, or translation within the same cell, or may only participate in some functions in certain cell types. In the case of QK, the three isoforms differ in amino acid sequence only at their C-termini, and this is thought to confer, in part, their distinct localization behaviors. QK-5, the predominantly nuclear form, seems more likely to be involved in direct splicing regulation (this work), whereas the cytoplasmic QK-6 and QK-7 forms may mediate translational control or mRNA stability with indirect effects on splicing (Saccomanno et al. 1999; Zhao et al. 2010; Zearfoss et al. 2011). We currently lack an understanding of the information that specifies which family member or isoform should bind where, or carry out which function. One possibility is that different family members or protein isoforms carry out these different functions, perhaps interacting with separate sets of adaptor proteins that confer specificity. But whether and how these distinct isoforms might be partitioned to different RNA target sites is unknown.

\section{Combinatorial control of the myogenic splicing program by $\mathrm{QK}$ and PTB}

To understand the relationship between the QK and PTB splicing regulatory networks in myoblasts and during differentiation, we defined the PTB global splicing network in undifferentiated myoblasts and differentiated myotubes using splicing sensitive microarrays. The PTB network is about 2.5 times larger than the QK network; while only $17 \%$ of PTB regulated exons are also controlled by QK, PTB coregulates nearly $42 \%$ of the QK network. The 172 exons coregulated by QK and PTB are split evenly into four classes: one where both repress, another where both activate, one where QK represses while PTB activates, and one where QK activates and PTB represses. Thus, for just over half of exons regulated by both proteins, they oppose each other and reinforce each other at the remaining exons. Analysis of the genes containing these regulated exons indicates that a diversity of both general and muscle-specific functions are under control of these factors.

During differentiation, the two proteins change levels in opposite directions, with QK increasing and PTB decreasing (Fig. 6) due in part to the induction of miR-133 and its repression of PTB mRNA (Boutz et al. 2007a). Exons such as $C a p z b$ exon 9 are activated during differentiation by the combined increase in QK activation and decrease of repression by PTB. However, numerous other splicing factors play roles in controlling alternative splicing in muscle, and given the complex interplay of splicing factors at most exons, dissecting a developmental program of alternative splicing will involve understanding not just why exons change inclusion levels, but how those that do not change are made stable (Fig. 6B). Nonetheless, by mapping splicing regulatory networks in myoblasts and following changes in factor level during differentiation, $\sim 22 \%-29 \%$ of the alternative splicing changes during myogenesis occur in a fashion consistent with primary regulation by QK alone, PTB alone, or the two proteins together. The close physical proximity of mapped PTB and 
QK motifs (Fig. 5, cf. Supplemental Fig. 2) in the sequence upstream of exons repressed by both proteins is notable and may indicate a mechanism whereby the relative occupancy and competition for binding plays a key role in the bimodal relationship between the two proteins-i.e., as one protein leaves another is able to bind. Future work will involve integrating our understanding of the roles of these and other splicing factors during myoblast differentiation, including MBNL1 (which also activates Capzb exon 9) (Du et al. 2010), RBFOX proteins, and the CELF proteins (Gromak et al. 2003). In addition, the control of PTB levels by miR-133 during myogenic differentiation (Boutz et al. 2007a) and the interactions between QK and microRNAs in other systems (Chen et al. 2012; Ji et al. 2012; van Mil et al. 2012) suggest that a full understanding of the developmental control of alternative splicing will require expanding our appreciation for other control mechanisms at the same time as we dissect the roles of splicing networks.

\section{MATERIALS AND METHODS}

\section{Cell culture}

Mouse C2C12 myoblast cells (ATCC) were maintained in Dulbecco's modified Eagle's medium (DMEM) supplemented with $10 \%$ fetal bovine serum (FBS, Invitrogen). To induce myogenesis, $1.5 \times 10^{5}$ cells were plated in growth medium (DMEM + 10\% FBS) in 6-well tissue culture-treated plates $12-18 \mathrm{~h}$ before addition of differentiation medium (DMEM supplemented with $2 \%$ horse serum, Invitrogen). Media was changed every $24 \mathrm{~h}$, and myotube formation was visible after $\sim 48 \mathrm{~h}$. Differentiation was verified visually by myotube formation and Western blot of myogenic markers. RNA and protein were isolated under subconfluent conditions in growth media (for myoblast analyses) or $72 \mathrm{~h}$ after addition of differentiation medium (for differentiation analyses).

\section{Microscopy}

Live cells were photographed on a Zeiss Axiovert 200 microscope using a Zeiss $20 \times / 0.30 \mathrm{LD}$ A-Plan lens. Images were collected using a SPOT Insight Mosaic 3.2.0 color digital camera and SPOT Advanced software (Diagnostic Instruments, Inc).

\section{Transient transfection}

Transfections were performed with Lipofectamine 2000 (Invitrogen) according to the manufacturer's instructions. Cells were incubated for 18-24 h post-transfection prior to harvesting RNA and/or protein.

\section{RNA isolation}

Whole-cell RNA was isolated using Trizol (Invitrogen) according to manufacturer's instructions. RNA pellets were resuspended in $50 \mu \mathrm{L}$ of TE (10 mM Tris, pH 8.0; 1 mM EDTA). Cytoplasmic RNA was extracted as described previously (Modafferi and Black 1997).

\section{Protein isolation}

Cells were harvested by trypsinization and washed once with $1 \times$ PBS, then resuspended in $50 \mu \mathrm{L}$ of NP-40 lysis buffer $(150 \mathrm{mM}$ $\mathrm{NaCl}, 10 \mathrm{mM}$ tris- $\mathrm{HCl}$ at $\mathrm{pH} 7.8,0.65 \% \mathrm{NP}-40$ ) with complete protease inhibitor cocktail tablets (Roche), and incubated on ice for 10 min. After spinning for $10 \mathrm{~min}$ at $18,000 \mathrm{~g}$ at $4^{\circ} \mathrm{C}$, the supernatant was flash frozen and stored at $-80^{\circ} \mathrm{C}$.

\section{Splicing microarrays}

Targets were prepared from three replicate cultures for each sample with the RiboMinus Kit (Invitrogen) and the GeneChip Whole Transcript Sense Target Labeling Kit (Affymetrix) Labeled target was hybridized to the MJAY Chip (Affymetrix \#540092). Chips were washed and scanned using the Fluidics Station 450 and GeneChip scanner (Affymetrix). Data were analyzed as in Sugnet et al. (2006). The Sepscore is $\log 2$ (Include/Skip ratio) of the experimental sample over the reference sample. When exon inclusion increases the Sepscore is positive. Hierarchical clustering (Eisen et al. 1998) was done with Cluster 3.0 (http://bonsai.hgc.jp/ mdehoon/ software/cluster/software.htm); clusters were displayed with Java TreeView (Saldanha 2004) (http://jtreeview.sourceforge.net/).

\section{Motif analysis}

Counts of all 5-mers in the selected region of an exon set are compared with their counts from a background set of sequences using Fisher's exact test, with multiple testing correction. Motif mapping is described in the Supplemental Methods.

\section{RNA affinity chromatography}

RNA was bound to beads and incubated with nuclear extract as described in the Supplemental Methods.

\section{Multidimensional Protein Identification Technology (MudPIT)}

Mass spectrometry was performed by the Vincent J. Coates Proteomics/Mass Spectrometry Laboratory at UC Berkeley. Peptides were eluted using a 14-step MudPIT procedure (Washburn et al. 2001). The programs SEQUEST and DTASELECT were used to identify peptides and proteins from the mouse database (Eng et al. 1994; Tabb et al. 2002). The false-positive rate for protein identification is calculated to be $<0.1 \%$ (Elias et al. 2005; Sharma et al. 2008). Detailed methodology is in the Supplemental Methods.

\section{RT-PCR}

cDNA synthesis and PCR details are in the Supplemental Methods; primer sequences are in Supplemental Table 9. Percent exon inclusion ([inclusion/(inclusion + skipping) $] \times 100$ ) is graphed in Excel; error bars are $\pm \mathrm{SD}$ for $n \geq 3$ independent experiments.

\section{DATA DEPOSITION}

Microarray data are deposited in the Gene Expression Omnibus (GEO) database under the accession number GSE40962. 


\section{SUPPLEMENTAL MATERIAL}

Supplemental material is available for this article.

\section{ACKNOWLEDGMENTS}

We thank Doug Black (Dept. of Microbiology, Immunology and Molecular Genetics, UCLA) and Sean Ryder (Dept. of Biochemistry and Molecular Pharmacology, UMass Medical School) for reagents and helpful advice. Dr. Lori Kohlstaedt (NIH grant 1S10RR025622-01) was a great help with MuDPIT. R.N. and M.H. had postdoctoral fellowships from the California Institute of Regenerative Medicine. This work was supported by NIH training grant TG 5T32GM008646-14 (W.S.F.), MDA135140 from the Muscular Dystrophy Association, NIH grant GM084317, and NIH grant GM040478 to M.A.

Received January 17, 2013; accepted February 20, 2013.

\section{REFERENCES}

Arning S, Gruter P, Bilbe G, Kramer A. 1996. Mammalian splicing factor SF1 is encoded by variant cDNAs and binds to RNA. RNA 2: 794-810.

Baehrecke EH. 1997. who encodes a KH RNA binding protein that functions in muscle development. Development 124: 1323-1332.

Beuck C, Qu S, Fagg WS, Ares M Jr, Williamson JR. 2012. Structural analysis of the Quaking homodimerization interface. $J$ Mol Biol 423: 766-781.

Black DL. 2003. Mechanisms of alternative pre-messenger RNA splicing. Annu Rev Biochem 72: 291-336.

Bland CS, Wang ET, Vu A, David MP, Castle JC, Johnson JM, Burge CB, Cooper TA. 2010. Global regulation of alternative splicing during myogenic differentiation. Nucleic Acids Res 38: 7651-7664.

Boutz PL, Chawla G, Stoilov P, Black DL. 2007a. MicroRNAs regulate the expression of the alternative splicing factor $\mathrm{nPTB}$ during muscle development. Genes Dev 21: 71-84.

Boutz PL, Stoilov P, Li Q, Lin CH, Chawla G, Ostrow K, Shiue L, Ares M Jr, Black DL. 2007b. A post-transcriptional regulatory switch in polypyrimidine tract-binding proteins reprograms alternative splicing in developing neurons. Genes Dev 21: 1636-1652.

Carmel AB, Wu J, Lehmann-Blount KA, Williamson JR. 2010. High-affinity consensus binding of target RNAs by the STAR/GSG proteins GLD-1, STAR-2 and Quaking. BMC Mol Biol 11: 48.

Chan RC, Black DL. 1997. The polypyrimidine tract binding protein binds upstream of neural cell-specific c-src exon N1 to repress the splicing of the intron downstream. Mol Cell Biol 17: 4667-4676.

Charizanis K, Lee KY, Batra R, Goodwin M, Zhang C, Yuan Y, Shiue L, Cline M, Scotti MM, Xia G, et al. 2012. Muscleblind-like 2-mediated alternative splicing in the developing brain and dysregulation in myotonic dystrophy. Neuron 75: 437-450.

Charlet-B N, Logan P, Singh G, Cooper TA. 2002. Dynamic antagonism between ETR-3 and PTB regulates cell type-specific alternative splicing. Mol Cell 9: 649-658.

Chen T, Richard S. 1998. Structure-function analysis of Qk1: A lethal point mutation in mouse quaking prevents homodimerization. Mol Cell Biol 18: 4863-4871.

Chen AJ, Paik JH, Zhang H, Shukla SA, Mortensen R, Hu J, Ying H, Hu B, Hurt J, Farny N, et al. 2012. STAR RNA-binding protein Quaking suppresses cancer via stabilization of specific miRNA. Genes Dev 26: 1459-1472.

Chénard CA, Richard S. 2008. New implications for the QUAKING RNA binding protein in human disease. J Neurosci Res 86: 233-242.

Corioni M, Antih N, Tanackovic G, Zavolan M, Kramer A. 2011. Analysis of in situ pre-mRNA targets of human splicing factor SF1 reveals a function in alternative splicing. Nucleic Acids Res 39: 1868-1879.

Crawford JB, Patton JG. 2006. Activation of $\alpha$-tropomyosin exon 2 is regulated by the SR protein $9 \mathrm{G} 8$ and heterogeneous nuclear ribonucleoproteins H and F. Mol Cell Biol 26: 8791-8802.
Das D, Clark TA, Schweitzer A, Yamamoto M, Marr H, Arribere J, Minovitsky S, Poliakov A, Dubchak I, Blume JE, et al. 2007. A correlation with exon expression approach to identify cis-regulatory elements for tissue-specific alternative splicing. Nucleic Acids Res 35: 4845-4857.

Di Fruscio M, Chen T, Richard S. 1999. Characterization of Sam68-like mammalian proteins SLM-1 and SLM-2: SLM-1 is a Src substrate during mitosis. Proc Natl Acad Sci 96: 2710-2715.

Dominski Z, Kole R. 1991. Selection of splice sites in pre-mRNAs with short internal exons. Mol Cell Biol 11: 6075-6083.

Du H, Cline MS, Osborne RJ, Tuttle DL, Clark TA, Donohue JP, Hall MP, Shiue L, Swanson MS, Thornton CA, et al. 2010. Aberrant alternative splicing and extracellular matrix gene expression in mouse models of myotonic dystrophy. Nat Struct Mol Biol 17: 187-193.

Ebersole TA, Chen Q, Justice MJ, Artzt K. 1996. The quaking gene product necessary in embryogenesis and myelination combines features of RNA binding and signal transduction proteins. Nat Genet 12: 260-265.

Eisen MB, Spellman PT, Brown PO, Botstein D. 1998. Cluster analysis and display of genome-wide expression patterns. Proc Natl Acad Sci 95: 14863-14868.

Elias JE, Haas W, Faherty BK, Gygi SP. 2005. Comparative evaluation of mass spectrometry platforms used in large-scale proteomics investigations. Nat Methods 2: 667-675.

Eng J, McCormack AL, Yates JR. 1994. An approach to correlate tandem mass spectral data of peptides with amino acid sequences in a protein database. Am Soc Mass Spectrom 5: 976-989.

Francis R, Barton MK, Kimble J, Schedl T. 1995. gld-1, a tumor suppressor gene required for oocyte development in Caenorhabditis elegans. Genetics 139: 579-606.

Fyrberg C, Becker J, Barthmaier P, Mahaffey J, Fyrberg E. 1997. A Drosophila muscle-specific gene related to the mouse quaking locus. Gene 197: 315-323.

Galarneau A, Richard S. 2005. Target RNA motif and target mRNAs of the Quaking STAR protein. Nat Struct Mol Biol 12: 691-698.

Goo Y-H, Cooper TA. 2009. CUGBP2 directly interacts with U2 17S snRNP components and promotes U2 snRNA binding to cardiac troponin T pre-mRNA. Nucleic Acids Res 37: 4275-4286.

Gooding C, Roberts GC, Smith CW. 1998. Role of an inhibitory pyrimidine element and polypyrimidine tract binding protein in repression of a regulated $\alpha$-tropomyosin exon. RNA 4: 85-100.

Gromak N, Matlin AJ, Cooper TA, Smith CWJ. 2003. Antagonistic regulation of $\alpha$-actinin alternative splicing by CELF proteins and polypyrimidine tract binding protein. RNA 9: 443-456.

Hafner M, Landthaler M, Burger L, Khorshid M, Hausser J, Berninger P, Rothballer A, Ascano M Jr, Jungkamp AC, Munschauer M, et al. 2010. Transcriptome-wide identification of RNA-binding protein and microRNA target sites by PAR-CLIP. Cell 141: 129-141.

Huh GS, Hynes RO. 1994. Regulation of alternative pre-mRNA splicing by a novel repeated hexanucleotide element. Genes Dev 8: 1561-1574.

Ji S, Ye G, Zhang J, Wang L, Wang T, Wang Z, Zhang T, Wang G, Guo Z, Luo Y, et al. 2012. miR-574-5p negatively regulates $Q k i 6 / 7$ to impact $\beta$-catenin/Wnt signalling and the development of colorectal cancer. Gut doi: 10.1136/gutjnl-2011-301083.

Jin Y, Suzuki H, Maegawa S, Endo H, Sugano S, Hashimoto K, Yasuda K, Inoue K. 2003. A vertebrate RNA-binding protein Fox-1 regulates tissue-specific splicing via the pentanucleotide GCAUG. EMBO J 22: 905-912.

Kalsotra A, Cooper TA. 2011. Functional consequences of developmentally regulated alternative splicing. Nat Rev Genet 12: 715-729.

Kramer A. 1992. Purification of splicing factor SF1, a heat-stable protein that functions in the assembly of a presplicing complex. Mol Cell Biol 12: 4545-4552.

Lakiza O, Frater L, Yoo Y, Villavicencio E, Walterhouse D, Goodwin EB, Iannaccone P. 2005. STAR proteins quaking-6 and GLD-1 regulate translation of the homologues GLI1 and tra-1 through a conserved RNA 3'UTR-based mechanism. Dev Biol 287: 98-110.

Lejeune F, Maquat LE. 2005. Mechanistic links between nonsense-mediated mRNA decay and pre-mRNA splicing in mammalian cells. Curr Opin Cell Biol 17: 309-315. 
Lewis BP, Green RE, Brenner SE. 2003. Evidence for the widespread coupling of alternative splicing and nonsense-mediated mRNA decay in humans. Proc Natl Acad Sci 100: 189-192.

Li Z, Zhang Y, Li D, Feng Y. 2000. Destabilization and mislocalization of myelin basic protein mRNAs in quaking dysmyelination lacking the QKI RNA-binding proteins. J Neurosci 20: 4944-4953.

Lim LP, Sharp PA. 1998. Alternative splicing of the fibronectin EIIIB exon depends on specific TGCATG repeats. Mol Cell Biol 18: 3900-3906.

Liu Z, Luyten I, Bottomley MJ, Messias AC, Houngninou-Molango S, Sprangers R, Zanier K, Kramer A, Sattler M. 2001. Structural basis for recognition of the intron branch site RNA by splicing factor 1 . Science 294: 1098-1102.

Llorian M, Schwartz S, Clark TA, Hollander D, Tan LY, Spellman R, Gordon A, Schweitzer AC, de la Grange P, Ast G, et al. 2010. Position-dependent alternative splicing activity revealed by global profiling of alternative splicing events regulated by PTB. Nat Struct Mol Biol 17: 1114-1123.

Lobbardi R, Lambert G, Zhao J, Geisler R, Kim HR, Rosa FM. 2011. Fine-tuning of $\mathrm{Hh}$ signaling by the RNA-binding protein Quaking to control muscle development. Development 138: 1783-1794.

Lock P, Fumagalli S, Polakis P, McCormick F, Courtneidge SA. 1996. The human p62 cDNA encodes Sam68 and not the RasGAP-associated p62 protein. Cell 84: 23-24.

Masuda A, Andersen HS, Doktor TK, Okamoto T, Ito M, Andresen BS, Ohno K. 2012. CUGBP1 and MBNL1 preferentially bind to $3^{\prime}$ UTRs and facilitate mRNA decay. Sci Rep 2: 209.

Modafferi EF, Black DL. 1997. A complex intronic splicing enhancer from the c-src pre-mRNA activates inclusion of a heterologous exon. Mol Cell Biol 17: 6537-6545.

Ni JZ, Grate L, Donohue JP, Preston C, Nobida N, O’Brien G, Shiue L, Clark TA, Blume JE, Ares M. 2007. Ultraconserved elements are associated with homeostatic control of splicing regulators by alternative splicing and nonsense-mediated decay. Genes Dev 21: 708-718.

Nilsen TW, Graveley BR. 2010. Expansion of the eukaryotic proteome by alternative splicing. Nature 463: 457-463.

Ohno G, Hagiwara M, Kuroyanagi H. 2008. STAR family RNA-binding protein ASD-2 regulates developmental switching of mutually exclusive alternative splicing in vivo. Genes Dev 22: 360-374.

Rodrigues F, Thuma L, Klambt C. 2012. The regulation of glial-specific splicing of Neurexin IV requires HOW and Cdk12 activity. Development 139: 1765-1776.

Ryder SP, Williamson JR. 2004. Specificity of the STAR/GSG domain protein Qk1: Implications for the regulation of myelination. RNA 10: $1449-1458$.

Ryder SP, Frater L, Abramovitz DL, Goodwin EB, Williamson JR. 2004. RNA target specificity of the STAR/GSG domain post-transcriptional regulatory protein GLD-1. Nat Struct Mol Biol 11: 20-28.

Saccomanno L, Loushin C, Jan E, Punkay E, Artzt K, Goodwin EB. 1999. The STAR protein QKI-6 is a translational repressor. Proc Natl Acad Sci 96: 12605-12610.

Saldanha AJ. 2004. Java Treeview-extensible visualization of microarray data. Bioinformatics 20: 3246-3248.

Sanford JR, Ellis J, Caceres JF. 2005. Multiple roles of arginine/serine-rich splicing factors in RNA processing. Biochem Soc Trans 33: 443-446.

Schafer DA, Korshunova YO, Schroer TA, Cooper JA. 1994. Differential localization and sequence analysis of capping protein $\beta$-subunit isoforms of vertebrates. J Cell Biol 127: 453-465.

Sharma S, Kohlstaedt LA, Damianov A, Rio DC, Black DL. 2008. Polypyrimidine tract binding protein controls the transition from exon definition to an intron defined spliceosome. Nat Struct Mol Biol 15: 183-191.

Sidman R, Dickie M, Appel S. 1964. Mutant mice (quaking and jimpy) with deficient myelination in the central nervous system. Science 144: 309-311.

Southby J, Gooding C, Smith CWJ. 1999. Polypyrimidine tract binding protein functions as a repressor to regulate alternative splicing of $\alpha$ actinin mutally exclusive exons. Mol Cell Biol 19: 2699-2711.

Sugnet CW, Srinivasan K, Clark TA, O’Brien G, Cline MS, Wang H, Williams A, Kulp D, Blume JE, Haussler D, et al. 2006. Unusual in- tron conservation near tissue-regulated exons found by splicing microarrays. PLoS Comput Biol 2: e4.

Tabb D, McDonald W, Yates JR. 2002. DTASelect and Contrast: Tools for assembling and comparing protein identifications from shotgun proteomics. J Proteome Res 1: 21-26.

Tanaka H, Abe K, Kim CH. 1997. Cloning and expression of the quaking gene in the zebrafish embryo. Mech Dev 69: 209-213.

Tang ZZ, Zheng S, Nikolic J, Black DL. 2009. Developmental control of CaV1.2 L-type calcium channel splicing by Fox proteins. Mol Cell Biol 29: 4757-4765.

Trapnell C, Williams BA, Pertea G, Mortazavi A, Kwan G, van Baren MJ, Salzberg SL, Wold BJ, Pachter L. 2010. Transcript assembly and quantification by RNA-Seq reveals unannotated transcripts and isoform switching during cell differentiation. Nat Biotechnol 28: 511-515.

Ule J, Stefani G, Mele A, Ruggiu M, Wang X, Taneri B, Gaasterland T, Blencowe BJ, Darnell RB. 2006. An RNA map predicting Nova-dependent splicing regulation. Nature 444: 580-586.

van Mil A, Grundmann S, Goumans MJ, Lei Z, Oerlemans MI, Jaksani S, Doevendans PA, Sluijter JP. 2012. MicroRNA-214 inhibits angiogenesis by targeting Quaking and reducing angiogenic growth factor release. Cardiovasc Res 93: 655-665.

Vernet C, Artzt K. 1997. STAR, a gene family involved in signal transduction and activation of RNA. Trends Genet 13: 479-484.

Voelker RB, Berglund JA. 2007. A comprehensive computational characterization of conserved mammalian intronic sequences reveals conserved motifs associated with constitutive and alternative splicing. Genome Res 17: 1023-1033.

Wang ET, Cody NA, Jog S, Biancolella M, Wang TT, Treacy DJ, Luo S, Schroth GP, Housman DE, Reddy S, et al. 2012. Transcriptome-wide regulation of pre-mRNA splicing and $\mathrm{mRNA}$ localization by muscleblind proteins. Cell 150: 710-724.

Warf MB, Diegel JV, von Hippel PH, Berglund JA. 2009. The protein factors MBNL1 and U2AF65 bind alternative RNA structures to regulate splicing. Proc Natl Acad Sci 106: 9203-9208.

Washburn MP, Wolters D, Yates JR. 2001. Large-scale analysis of the yeast proteome by multidimensional protein identification technology. Nat Biotechnol 19: 242-247.

Wu J, Zhou L, Tonissen K, Tee R, Artzt K. 1999. The quaking I-5 protein (QKI-5) has a novel nuclear localization signal and shuttles between the nucleus and the cytoplasm. J Biol Chem 274: 29202-29210.

Xue Y, Zhou Y, Wu T, Zhu T, Ji X, Kwon YS, Zhang C, Yeo G, Black DL, Sun H, et al. 2009. Genome-wide analysis of PTB-RNA interactions reveals a strategy used by the general splicing repressor to modulate exon inclusion or skipping. Mol Cell 36: 996-1006.

Yates J, Ruse CI, Nakorchevsky A. 2009. Proteomics by mass spectrometry: Approaches, advances, and applications. Annu Rev Biomed Eng 11: 49-79.

Yeo GW, Nostrand ELV, Liang TY. 2007. Discovery and analysis of evolutionarily conserved intronic splicing regulatory elements. PLoS Genet 3: e85.

Yeo GW, Coufal NG, Liang TY, Peng GE, Fu XD, Gage FH. 2009. An RNA code for the FOX2 splicing regulator revealed by mapping RNA-protein interactions in stem cells. Nat Struct Mol Biol 16: 130-137.

Zaffran S, Astier M, Gratecos D, Semeriva M. 1997. The held out wings (how) Drosophila gene encodes a putative RNA-binding protein involved in the control of muscular and cardiac activity. Development 124: 2087-2098.

Zearfoss NR, Clingman CC, Farley BM, McCoig LM, Ryder SP. 2011. Quaking regulates Hnrnpal expression through its 3' UTR in oligodendrocyte precursor cells. PLoS Genet 7: e1001269.

Zhang C, Zhang Z, Castle J, Sun S, Johnson J, Krainer AR, Zhang MQ. 2008. Defining the regulatory network of the tissue-specific splicing factors Fox-1 and Fox-2. Genes Dev 22: 2550-2563.

Zhao L, Mandler MD, Yi H, Feng Y. 2010. Quaking I controls a unique cytoplasmic pathway that regulates alternative splicing of myelin-associated glycoprotein. Proc Natl Acad Sci 107: 19061-19066.

Zorn AM, Krieg PA. 1997. The KH domain protein encoded by quaking functions as a dimer and is essential for notochord development in Xenopus embryos. Genes Dev 11: 2176-2190. 

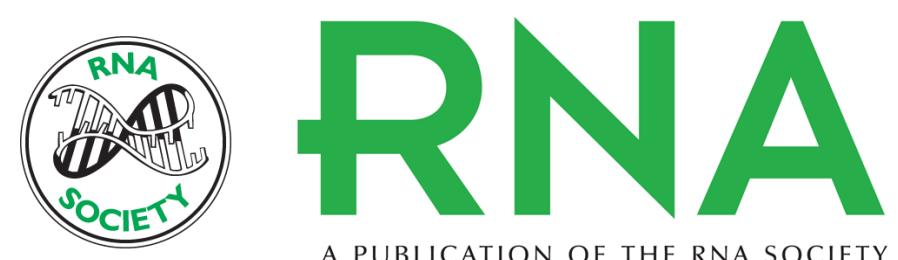

A PUBLICATION OF THE RNA SOCIETY

\section{Quaking and PTB control overlapping splicing regulatory networks during muscle cell differentiation}

Megan P. Hall, Roland J. Nagel, W. Samuel Fagg, et al.

RNA 2013 19: 627-638 originally published online March 22, 2013

Access the most recent version at doi:10.1261/rna.038422.113

Supplemental
Material http://rnajournal.cshlp.org/content/suppl/2013/03/14/rna.038422.113.DC1

References This article cites 82 articles, 40 of which can be accessed free at:

http://rnajournal.cshlp.org/content/19/5/627.full.html\#ref-list-1

License

Email Alerting Receive free email alerts when new articles cite this article - sign up in the box at the Service top right corner of the article or click here. 